\title{
Prediction of enophthalmos by computed tomography after 'blow out' orbital fracture
}

R W Whitehouse, M Batterbury, A Jackson, J L Noble

\begin{abstract}
In 11 patients with blow out fracture of the orbit, measurement of orbital volume using computed tomography (CT) more than 20 days after injury correlated well with enophthalmos measured from the same scans $(r=0.87$, $\mathrm{p}<0.001$, SEE $0.63 \mathrm{~mm}$ ), with a $1 \mathrm{~cm}^{3}$ increase in orbital volume causing $0.8 \mathrm{~mm}$ of enophthalmos. This confirms the cause of enophthalmos after blow out fracture to be increase in orbital volume rather than fat atrophy or fibrosis. In a further 25 patients scanned within 20 days of injury the degree of enophthalmos was less marked than would be predicted from the orbital volume measurement. This was probably because of the presence of oedema, haemorrhage, or both behind the globe which would prevent immediate development of enophthalmos. CT measurement of orbital volume within 20 days of injury may predict the final degree of enophthalmos and identify those patients at risk of late enophthalmos, allowing appropriate early surgical intervention.

(BrF Ophthalmol 1994; 78: 618-620)
\end{abstract}

Enophthalmos is a common result of 'blow out' fracture of the orbit. It is now widely accepted that enophthalmos results from an increase in volume of the bony orbit with consequent posterior displacement of the globe as the retrobulbar fat and muscles are displaced into the blow out defect. ${ }^{12}$ Other possible factors such as fat atrophy or fibrosis ${ }^{3}$ have not been demonstrated to contribute to a significant degree. Enophthalmos may be both cosmetically unacceptable and may cause diplopia by interfering with extraocular muscle function. ${ }^{+}$Enophthalmos may not develop immediately after trauma and its onset may occasionally be delayed for 2 months or more. ${ }^{56}$ Early surgical intervention can improve the outcome ${ }^{67}$ but identifying those patients at risk of late enophthalmos is problematic.

Computed tomography (CT) has been used to measure both orbital volume ${ }^{89}$ and enophthalmos ${ }^{19}$ in blow out fractures but a specific in vivo relation between these measurements has not been previously defined. The current study aims to evaluate the relation between orbital volume and enophthalmos following blow out fracture.

\section{Patients and methods}

The CT examinations of 36 consecutive patients attending the department of diagnostic radiology for assessment of orbital blow out fractures were reviewed. There were 13 orbital floor fractures, three medial wall fractures, and 21 combined

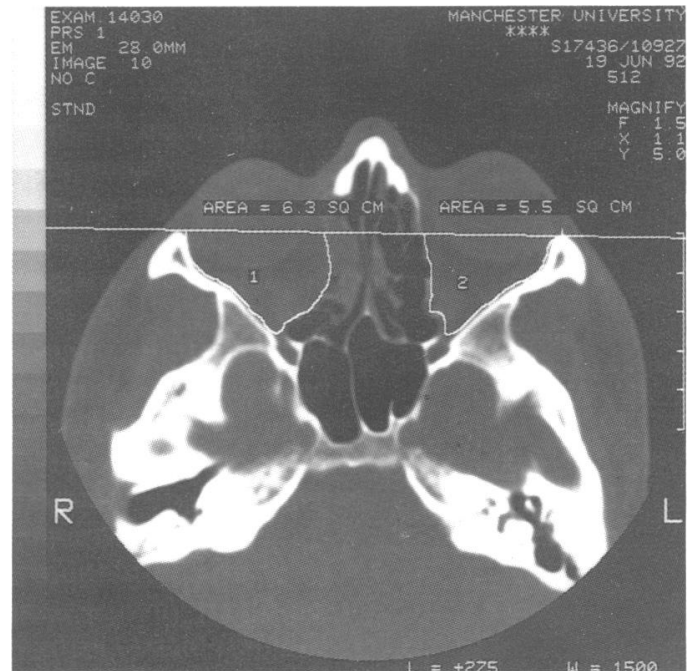

Figure 1 Transaxial low dose CT image of the orbits. A medial wall blow out fracture of the right orbit is present. The cross sectional area of each orbit has been measured for orbital volume calculation.

medial wall and floor fractures, the latter associated with malar fractures in two cases. All scans were performed on a GE9800 general purpose CT scanner (General Electric, Milwaukee, USA) using a low radiation dose dynamic transaxial scan technique as previously described ${ }^{10}$ (120 kVp, $40 \mathrm{~mA}, 2$ s scan time, $3 \mathrm{~mm}$ contiguous sections). Each orbital volume was measured on the CT console: On each image the bony outline of each orbit was traced out, the anterior limit being closed with a line joining the zygomaticofrontal processes (Fig 1). The areas of these outlines were then measured and summed for each orbit. Orbital volume was calculated from the summed area multiplied by the section

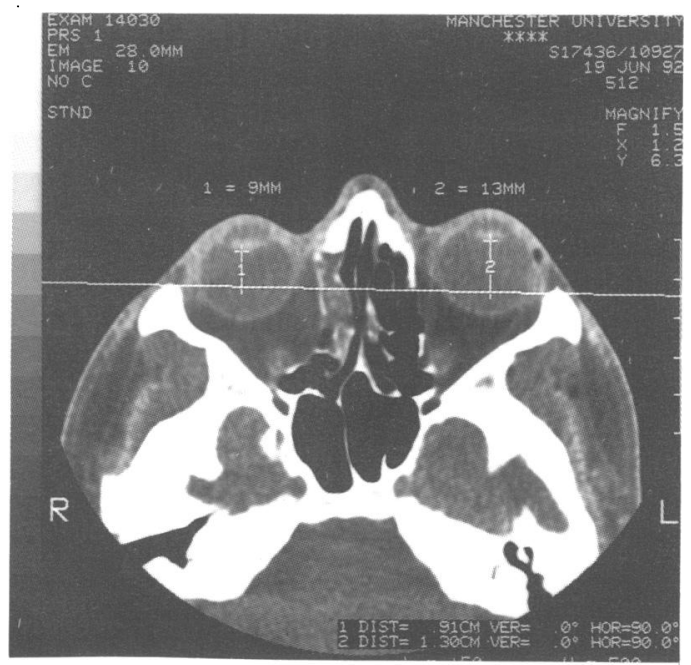

Figure 2 The position of each globe is measured from the zygomaticofrontal process baseline to the back of the lens (distances 1 and 2 ). 


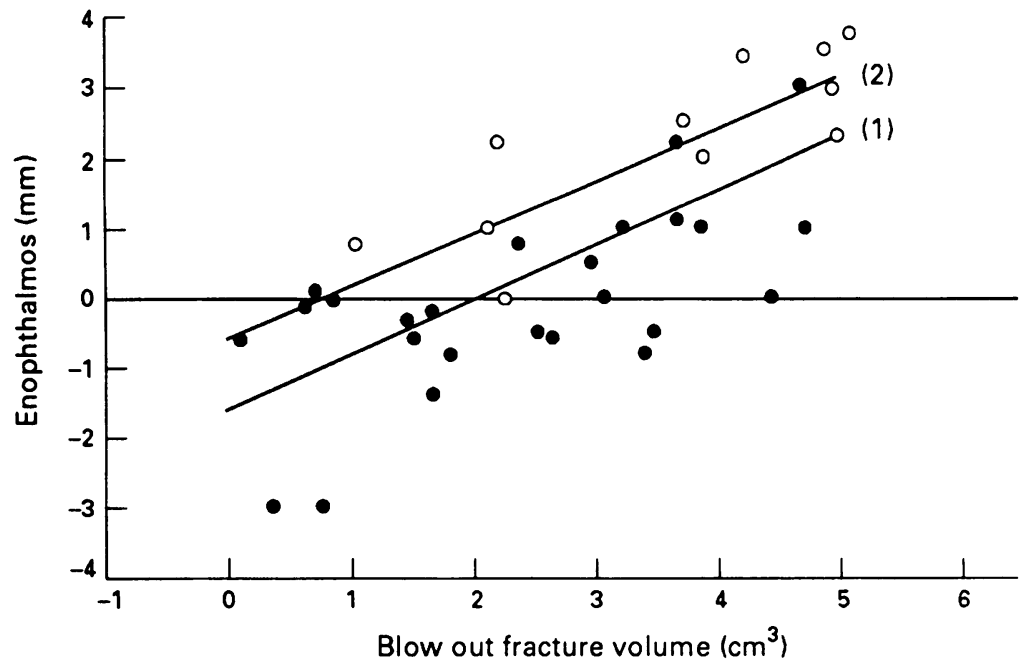

Figure 3 Relation between blow out fracture volume and enophthalmos. Line 1 is the regression for all 36 data points, line 2 is for points marked $(\bigcirc)$, scanned more than 20 days after injury.

Figure 4 Relation between unexplained enophthalmos and time since injury. $A \log _{10}$ time scale has been used to clarify the distribution of data points. The broken line indicates 20 days postinjury.

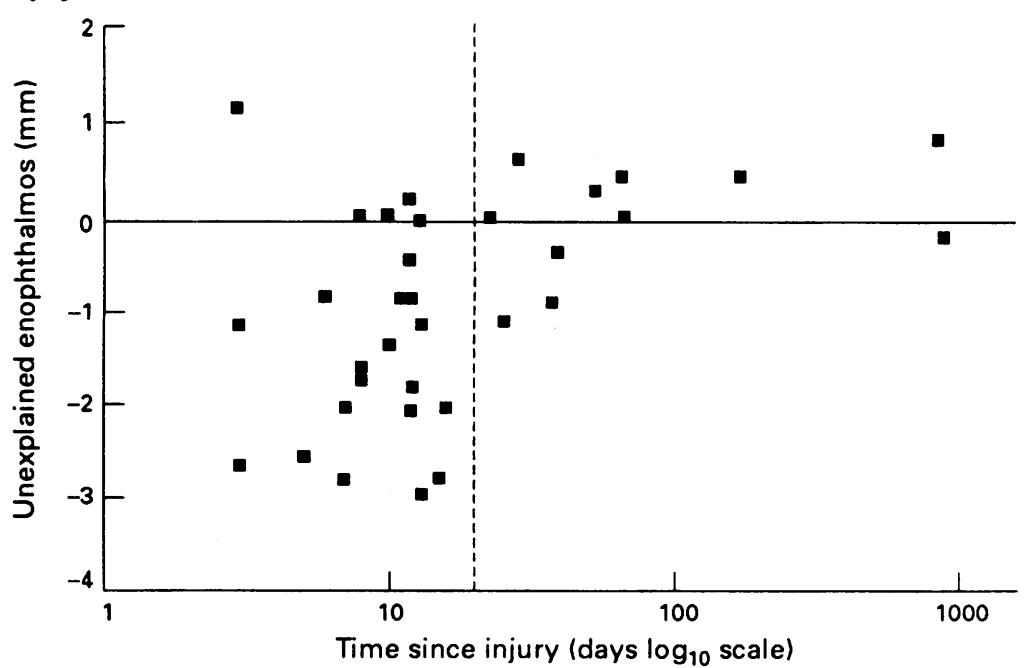
in volume between the traumatised and norm orbit volumes, as right and left orbital volumes in an individual normally lie within $0.65 \mathrm{~cm}^{3}$ of each other. ${ }^{11}{ }^{12}$ Globe position was measured from the same zygomaticofrontal process baseline to the posterior surface of the lens in each orbit (Fig 2), enophthalmos being the normal eye distance minus the traumatised eye distance.

\section{STATISTICAL TESTS}

The relation between enophthalmos and orbital volume discrepancy was assessed using Pearson correlation coefficients.

\section{Results}

A highly significant correlation between blow out fracture volume and enophthalmos was demonstrated in the entire group of 36 subjects (Fig 3, regression line 1):

$$
\mathrm{E}=0.82 \mathrm{~V}-1.67
$$$$
r=0 \cdot 74, \mathrm{p}<0 \cdot 001 \text {, SEE } 1 \cdot 1 \mathrm{~mm}, \mathrm{n}=36
$$
where

$$
\begin{array}{ll}
\mathrm{E} & =\text { enophthalmos }(\mathrm{mm}) \\
\mathrm{V} & =\text { blow out fracture volume }\left(\mathrm{cm}^{3}\right) \\
\mathrm{SEE} & =\text { standard error of estimate }
\end{array}
$$

Figure 3 also demonstrates that a large proportion of patients (14/36), particularly those with smaller blow out fracture volumes had negative enophthalmos (exophthalmos) at the time of scanning.

When only scans performed more than 20 days after injury were included, the correlation improved with a similar slope but less negative intercept value to the regression formula (Fig 3, regression line 2):

$$
\begin{gathered}
\mathrm{E}=0.77 \mathrm{~V}-0.68 \\
r=0.87, \mathrm{p}<0.001, \text { SEE } 0.63 \mathrm{~mm}, \mathrm{n}=11
\end{gathered}
$$

In order to demonstrate the dependence on time after injury of the relation between orbital volume and enophthalmos, formula (2) was used to calculate the expected degree of enophthalmos from the measured blow out fracture volume for all 36 subjects. Unexplained enophthalmos was calculated as measured enophthalmos minus expected enophthalmos. Unexplained enophthalmos was then plotted against time since injury (Fig 4), using a logarithmic time axis to clarify the distribution of data points within 20 days of injury.

\section{Discussion}

The results of this study confirm that enophthalmos after blow out fracture of the orbit is linearly related to the increase in volume of the blown out orbit. This relation is consistent in injuries between 20 days and 2 years old, with each $\mathrm{cm}^{3}$ increase in volume causing approximately $0.77 \mathrm{~mm}$ of enophthalmos. Injuries less than 20 days old have a similar regression line slope (approximately $0.8 \mathrm{~mm}$ per $\mathrm{cm}^{3}$ ) but an intercept of -1.67 , indicating a coexisting tendency for relative exophthalmos in the traumatised orbit. This should be expected; it presumably represents the effect of soft tissue swelling in the retrobulbar soft tissues counteracting the increase in orbital volume caused by the blow out. Calculating unexplained enophthalmos quantifies the effect of this soft tissue swelling, which can then be plotted against time since injury (Fig 4). This graph demonstrates that enophthalmos may be less marked than expected by up to $3 \mathrm{~mm}$ within 20 days of injury. Thus up to $3 \mathrm{~mm}$ of enophthalmos may be obscured by retrobulbar soft tissue swelling after blow out fracture and this effect may still be apparent 20 days after injury. The volume change of $1 \mathrm{~cm}^{3}$ required to produce $0.8 \mathrm{~mm}$ of globe movement is greater than that predicted by an in vitro model $^{13}$ where a $2 \cdot 8 \%$ volume change (approximately $0.56 \mathrm{~cm}^{3}$ ) caused $1 \mathrm{~mm}$ of globe movement. This discrepancy may reflect some resistance to movement of the globe in vivo, perhaps because of its suspensory ligament attachments to the bony orbit. ${ }^{14}$ Alternatively, it may be due to the compartmentalisation of orbital fat, some of which may be displaced by a blow out fracture, without causing globe displacement. ${ }^{15}$ The cause of this discrepancy is of less practical importance than the recognition of the in vivo relation between orbital volume change and globe position; this may be used to assess the need for surgery or to estimate the volume of replacement material required to reduce enophthalmos. 
In a previous retrospective analysis we have demonstrated that surgery is more likely to be performed in patients with larger volume blow out fractures, ${ }^{16}$ confirming previous findings. ${ }^{17}$ The current study demonstrates that measurement of orbital volume within 20 days of injury may allow prediction of the final degree of enophthalmos from equation (2), thus allowing more precise identification and early surgical management of those patients with a high risk of late enophthalmos.

1 Bite U, Jackson IT, Forbes GS, Gehring DG. Orbital volume measurements in enophthalmos using three-dimensional CT imaging. Plast Reconstr Surg 1984; 75: 502-7.

2 Manson PN, Grivas A, Rosenbaum A, Morgan R Studies on enophthalmos II: The measurement of orbital injuries and enophthalmost Reconstr Surg 1986; 77: 203-14.

3 Pathria MN, Blaser SI. Diagnostic imaging of craniofacial fractures. Radiol Clin N Am 1989; 27: 839-53.

4 Koorneef L, Zonneveld FW. The role of direct multiplanar high resolution CT in the assessment and management of high resolution CT in the assessment and managem

orbital trauma. Radiol Clin N Am 1987; 25: 753-66.
Sanderov B, Viccellio P. Fractures of the medial orbital wall Ann Emerg Med 1988; 17: 973-6.

6 Hawes MJ, Dortzbach RK. Surgery on orbital floor fractures: influence of time or repair and fracture size. Ophthalmology 1983; 90: 1066-70.

7 Converse JM, Smith B. On the treatment of blow out fractures of the orbit. Plast Reconst Surg 1978; 62: 100-4

8 Forbes G, Gehring DG, Gorman CA, Brennan MD, Jackson IT. Volume measurements of normal orbital structures by computed tomographic analysis. Am F Roentgenol 1985; 145: 149-54.

9 Whitehouse RW, Jackson A. Measurement of orbital volumes following trauma using low dose computed tomography. Eur Radiol 1993; 3: 145-9.

10 Jackson A, Whitehouse RW. Low dose computed tomography imaging in orbital trauma. Br $\mathcal{F}$ Radiol 1993; 66: 655-61.

11 McGurk M, Whitehouse RW, Taylor PM, Swinson B. Orbital volume measured by a low dose CT scanning technique. Dentomaxillofacial Radiol 1992; 21: 70-2.

12 Cooper WC. A method for volume determination of the orbi and its contents by high resolution axial tomography an quantitative digital image analysis. Trans Am Ophthalmol Soc 1985; 33: 546-610.

13 Parsons GS, Mathog RH. Orbital wall and volume relationMhips. Arch Otolarymgol Head Neck Surg 1988; 114: 743-7.

14 Manson PN, Clifford CM, Su CT, Iliff NT, Morgan R. Mechanisms of global support and postraumatic enophMes: I. The anatomy of the ligament sling and its relation to intramuscular cone orbital fat. Plast Reconstr Surg 1986; 77: 194-202.

15 Pearl RM. Surgical management of volumetric changes in the bony orbit. Ann Plast Surg 1987; 19: 349-58.

16 Charteris DG, Chan C-H, Whitehouse RW, Noble JL. Orbital volume measurement in the management of pure blow out fractures of the orbital floor. $\mathrm{Br} \mathcal{F}$ Ophthalmol 1993; 77 $100-2$.

17 Hammerschlag SB, Hughes S, O'Reilly GV, Weisler AL Another look at blow out fractures of the orbit. Am Roentgenol 1982; 139: 133-7. 